\title{
On the matter of fluorescence bronchoscopy
}

\author{
M. Patelli, D. Paioli, R. Trisolini
}

Monaldi Arch Chest Dis 2004; 61: 2, 78-79.

Unit of Thoracic Endoscopy, Maggiore Hospital, Bologna, Italy.

Correspondence: Marco Patelli, MD, FCCP; Unit of Thoracic Endoscopy, Maggiore Hospital, Largo Nigrisoli 2, 40133 Bologna, Italy; e-mail:marco.patelli@ausl.bologna.it

Lung cancer represents a major health problem worldwide, with 5-yr survival rates ranging from $5 \%$ to $15 \%$. As better prospects of treatment are offered through surgery, which in turn is more likely to be curative in the early stages, considerable efforts have been made in recent decades to develop methods which are able to detect pre-malignant and early malignant airway lesions. Among the various initiatives in this setting, autofluorescence bronchoscopy (AFB) - which works by exploiting differences in the fluorescence properties of normal and abnormal tracheobronchial mucosa after excitation with light of various wavelengths - has been extensively tested as a tool in detecting early lesions centrally located in the airways. Other possible applications of AFB include studies of molecular biology in pre-malignancy and early malignancy, chemoprevention studies, endobronchial therapy studies, localisation of synchronous tumours, evaluation of the extent of field cancerisation, and better estimation of the resection margins [1]. Many studies illustrating the results of AFB have appeared in the literature since 1997 and are available for review. A large, multicenter trial employing the LIFE system (LIFE, Xillix, Richmond, BC, Canada) has demonstrated a relative sensitivity of 2.7 for white light bronchoscopy (WLB) combined to AFL, as compared to WLB alone [2]. A more recent study by Herth and coll. [3] has compared the LIFE and the Dlight (D-light Storz, Karl Storz, Tuttlingen, Germany) systems, finding no significant differences in their ability to detect pre-malignant or early malignant lesions. It should be noted that both LIFE and D-light systems do not need fluorescence enhancing drugs.

In the late 70's and in the early 80's, before the aforementioned new AFL systems become available, some investigators addressed the possibility of diagnosing early airway lesions by exploiting tumour drug-specific fluorescence. Cortese and coll. [4], and Hayata et al. [5, 6] used hematoporphyrin derivative (Hpd) as a photosensitizer and the light developed from a krypton ion laser as light source. When Hpd is stimulated by the exciting light (e.g. $405 \mathrm{~nm}$ wavelength), it emits red flu- orescence with characteristic peaks at 630 and 690 $\mathrm{nm}$; the recognition of this fluorescence pattern allows the localisation of malignant tissue. The results of Hpd and photo-radiation using krypton ion laser beam were positive in $3 / 3$ cases of severe atypical squamous cell metaplasia and in $0 / 1$ case of mild metaplasia; the procedure was positive in $3 / 3$ cases of early stage cancer and in 30/33 cases of cancer in other stages.

In this issue of Monaldi Archives of Chest Diseases, Piotrowski and colleagues report their experience with photodynamic diagnostic bronchoscopy (PDD) in early detection of bronchial cancer. They examined 49 patients with present or past respiratory neoplasms, or with increased risk of bronchial cancer by photodynamic bronchoscopy (D-Light) performed after inhalation of $\delta$-aminolevulinic acid (5-ALA). The overall sensitivity was $82 \%$, specificity $62 \%$, positive predictive value (PPV) $45 \%$ and negative predictive value (NPV) $90 \%$. However, specificity decreased to $53 \%$ and PPV to $15 \%$ when visible tumours were excluded from the analysis. PDD, when added to WLB, increased sensitivity by $2.1 \%$ and NPV by $6 \%$, but decreased specificity by $35.4 \%$ and PPV by $53.1 \%$. In a group with actual or past respiratory tumours the sensitivity increased by $22 \%$ and NPV by $34 \%$, whereas specificity and PPV decreased by $26 \%$ and $35 \%$, respectively. The Authors conclude that the PDD may be useful for detection of early malignant changes in patient candidates to surgery for lung cancer (synchronous lesions and recognition of infiltration margins) and in the follow-up of patients already submitted to surgery for lung cancer (metachronous lesions and stump control).

By considering the results of this study, PDD provides yields very similar to those of AFB in the detection of pre-malignant and malignant tracheobronchial lesions, but is associated with additional disadvantages such as costs and availability of the fluorescence-enhancing drugs, possible drug-specific adverse effects, and increased duration of the procedure (the interval between inhalation of 5ALA and bronchoscopic examination was 3 hours in this study). 
The main limits and questions opened by the use of fluorescence bronchoscopy (FB) procedures remain unsolved, as outlined below, regardless of the technique used.

The high sensitivity of FB in detecting metaplasia and dysplasia have raised the very important clinical dilemma on how to manage these lesions, keeping in mind that their natural history is poorly understood [7]. Bota and colleagues [8] suggest that low-grade epithelial lesions could be safely followed-up for 2-yrs in patients without highgrade lesions at baseline, whereas severe dysplasia should be treated if it persists at 3 months. Banerjee and associates [9] elected to keep lesions of all grades of severity under surveillance, including carcinoma in situ, but to intervene at the earliest signs of progression to invasive disease; this approach would facilitate the identification of the molecular markers that can predict the behaviour of the lesions.

Another significant problem associated with FB is its low specificity, with rates of false positive biopsies ranging from 29 to $66 \%[2,10,11]$. In the study by Piotrowsky et al, specificity and PPV fall down to $53 \%$ and $15 \%$ respectively when visible tumours are excluded from the analysis. However, it has been suggested that up to $50 \%$ of the biopsies obtained from areas with abnormal fluorescence pattern carry molecular genetic lesions associated with malignancy, despite their non-neoplastic appearance [12]. Furthermore, Pasic et al. [13] have reported an increased risk of squamous cell carcinoma among patients with $\geq 3$ positive FB lesions at baseline, and have suggested the utility of accurate bronchoscopic surveillance. On the other side, repeated biopsies from areas with abnormal fluorescence pattern may induce significant iatrogenic changes such as the progression of epithelial lesions due to the major regenerative stimulus after sampling, the biopsy-induced secondary mucosal inflammation, the possible complete removal of small epithelial lesions [14].

In conclusion, FB is superior to WLB in the detection of precancerous lesions and central early lung cancer. FB has represented an important step forward in the setting of lung cancer since early lesions might be an important target for genetic research. What is more, the identification of patients with micro-invasive cancer should make curative treatment possible. Several studies have suggested that even local treatments (photodynamic therapy, brachitherapy, electrocautery and criotherapy) result in very favourable outcomes as primary approaches in patients with early malignant lesions of $<10 \mathrm{~mm}$ in greatest axis [15].

For the time being the autofluorescence bronchoscopy techniques (AFL) have to be considered superior to those employing fluorescence-enhancing drugs (PDD) since they provide comparable results but are less expensive and time-consuming.

\section{References}

1. Kennedy TC, Lam S, Hirsch FR. Review or recent advances in fluorescence bronchoscopy in early localization of central airway lung cancer. The Oncologist 2001; 6: 257-262.

2. Lam S, Kennedy T, Unger M. Localization of bronchial intraepithelial neoplastic lesions by fluorescence bronchoscopy. Chest 1998; 113: 696-702.

3. Herth FJF, Ernst A, Beker HD. Autofluorescence bronchoscopy - A comparison of two systems (LIFE and DLight). Respiration 2003; 70: 395-398.

4. Cortese DA, Kinsey JH, Woolner LB, Payne WS, Sanderson DR, Fontana RS. Clinical application of a new endoscopic technique for detection of in situ bronchial carcinoma. Mayo Clin Proc 54: 635-642, 1979.

5. Hayata Y, Kato H, Ono J, Matsushima Y, Hayashi N, SaitoT, Kawate N. Fluorescence fiberoptic bronchoscopy in the diagnosis of early lung cancer. In: Early detection and localization of lung tumors in high risk groups (P.R. Band, Ed.) Recent results in cancer research. Vol. 82, Springer-Verlag, Berlin, 1982, pp. 121130.

6. Hayata $\mathrm{Y}$, Kato H, Konaka C, Ono J, Matsushima Y, Yoneyama K, Nishimyia K. Fiberoptic bronchoscopic laser photoradiation for tumor localization in lung cancer. Chest 82: 10-14, 1982.

7. Banerjee AK, Rabbitts PH, George J. Lung Cancer. 3: Fluorescence bronchoscopy: clinical dilemmas and research opportunities. Thorax 2003; 58: 266-271.

8. Bota S, Auliac JB, Paris C, Metayer J, Sesboué R, Nouvet G, Thiberville L. Follow-up of bronchial precancerous lesions and carcinoma in situ using fluorescence endoscopy. Am J Respir Crit Care Med 2001; 164: 16881693.

9. Banerjee AK, Rabbits PH, Gorge PJ. Preinvasive bronchial lesions. Surveillance or intervention? Chest 2004: 125: 95S-96S.

10. Hirsch FR, Prindiville SA, Miller YE, Franklin WA, Dempsey EC, Murphy JR, Bunn PA, Kennedy TC. Fluorescence versus white-light bronchoscopy for detection of preneoplastic lesions: a randomized study. $J$ Nat Cancer Inst 2001; 93: 1385-1391.

11. Vermylen P, Pierard P, Roufosse C, Bosschaerts T, Verhest A, Sculier JP, Ninane V. Detection of preneoplastic lesions and early lung cancer with fluorescence bronchoscopy: a study about its ambulatory feasibility under local anaesthesis. Lung Cancer 1999; 25: 161168.

12. Wistuba II, Lam S, Behrens C, Virmani AK, Fong KM, LeRiche J, Samet JM, Srivastava S, Minna JD, Gazdar AF. Molecular damage in the bronchial epithelium of current and former smokers. J Natl Cancer Inst 1997; 89: 1366-1373.

13. Pasic A, Von-Noordegraaf A, Risse EKJ, Postmus PE, Sutedjia TG. Multiple suspicious lesions detected by autofluorescence bronchoscopy predict malignant development in the bronchial mucosa in high risk patients. Lung Cancer 2003; 41: 295-301.

14. Wockel W, Morresi-Hauff A. Regeneration of bronchial mucosa after short-term repetition of biopsy versus bronchial carcinoma. Pathologe 1997; 18: 488491.

15. Mathur PN, Edell E, Sutedjia T, Vergnon JM. Treatment of early stage non-small cell lung cancer. Chest 2003; 123: 176S-180S 